\title{
Facial Reanimation Procedures Depicted on Radiologic Imaging
}

\author{
D.T. Ginat, P. Bhama, M.E. Cunnane, and T.A. Hadlock
}

\begin{abstract}
SUMMARY: Various facial reanimation procedures can be performed for treating patients with chronic facial nerve paralysis. The radiologic imaging features of static and dynamic techniques are reviewed in this article with clinical correlation, including brow lift, eyelid weights and springs, gracilis free flaps, fascia lata grafts, temporalis flaps, and Gore-Tex suspension slings. Although the anatomic alterations resulting from facial reanimation surgery may not necessarily be the focus of the imaging examination, it is important to recognize such changes and be familiar with MR imaging compatibility of the associated implanted materials. Furthermore, imaging is sometimes used to specifically evaluate the postoperative results, such as vessel patency following free gracilis transfer.
\end{abstract}

C hronic facial nerve paralysis can result in significant morbidity, including brow ptosis, lagophthalmos, ectropion, exposure keratopathy, nasal alar collapse, effacement of the nasolabial fold, ptosis of the oral commissure, and drooling. Static and dynamic facial reanimation surgical techniques are available to prevent and treat these complications. Static facial nerve rehabilitation procedures include brow lift, eyelid weight implantation, lower eyelid canthoplasty and tightening, fascia lata and alloplastic slings, and cheiloplasty. Dynamic facial reanimation procedures include nerve transfer and grafting, eyelid springs, free muscle transfer, regional muscle transfer, and lengthening myoplasty. The anatomic changes brought about by these procedures can be delineated by using conventional radiologic imaging modalities, including radiographs, CT, sonography, and MR imaging. Furthermore, in certain instances, imaging may be requested specifically to evaluate the results of facial reanimation surgery, such as interrogating the patency of the vascular pedicle following gracilis muscle transfer. The imaging findings after selected static and dynamic facial reanimation surgeries are described and depicted in the following sections.

From the Department of Radiology (D.T.G.), Division of Neuroradiology, Massachusetts General Hospital, Boston, Massachusetts; and Department of Otolaryngology (P.B., T.A.H.), Division of Facial Plastic and Reconstructive Surgery, and Department of Radiology (M.E.C.), Massachusetts Eye and Ear Infirmary, Boston, Massachusetts. Please address correspondence to Daniel Thomas Ginat, MD, MS, University of Chicago, Department of Radiology, 5841 S. Maryland Ave, MC 2026, Rm. P220, Chicago, IL 60637; e-mail: ginatd01@gmail.com

- Indicates open access to non-subscribers at www.ajnr.org

http://dx.doi.org/10.3174/ajnr.A3684

\section{Brow Lift}

Brow ptosis can be addressed by performing a brow lift. Several methods exist to elevate the brow, one of which consists of implanting a fixation device into the frontal calvaria to which a permanent suture is secured (Fig 1). ${ }^{1}$ Brow lift can be performed in conjunction with ablation of the brow depressor muscles and blepharoplasty. Numerous fixation devices can be used, including pins, screws, tacks, K-wires, and tissue adhesives. Metallic fixation devices can be depicted on CT and should not be mistaken for unintended foreign bodies (Fig 2).

\section{Eyelid Weights}

Implantation of gold and platinum eyelid weights into the upper eyelid is a static reanimation procedure for treating lagophthalmos. ${ }^{2}$ Although gold weights are more commonly used, platinum weights have a thinner profile and therefore offer an increased aesthetic benefit. ${ }^{3}$ Available eyelid implant designs include curved metal sheets with holes to permit anchoring with a suture (Fig 3) and flexible metal chains. In-growth of fibrous tissue through the holes also helps secure the weight in position. Eyelid weights are secured to the superficial aspect of the upper eyelid tarsal plate. The eyelid weights generally produce considerable streak artifacts on CT, which can obscure surrounding structures (Fig 4). Platinum and gold eyelid weights are considered MR imaging-compatible up to $7 \mathrm{~T}^{4,5}$ but may cause local field inhomogeneity (Fig 5). Complications related to eyelid weight implantation include suboptimal eyelid contour, infection, allergic reaction, migration, and extrusion. ${ }^{6}$

\section{Eyelid Springs}

Eyelid springs are used to augment eyelid closure in patients with eyelid paralysis. ${ }^{7,8}$ The spring has the ability to achieve complete eye 

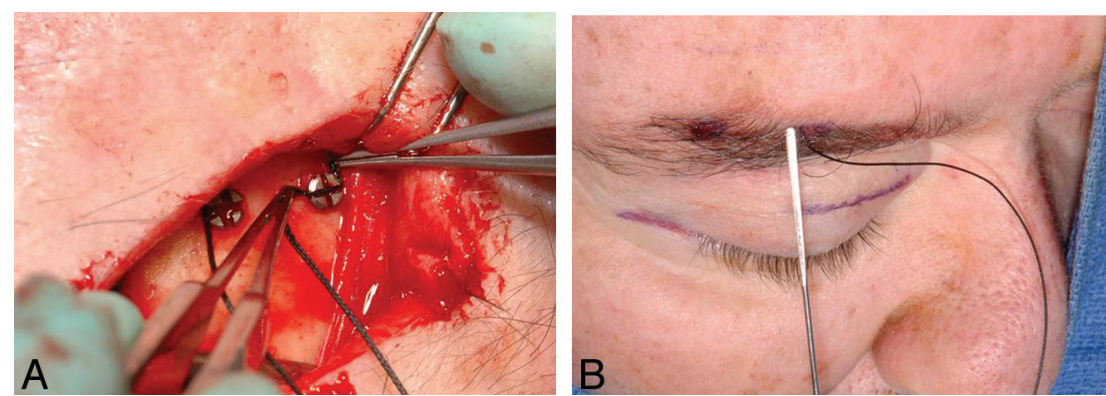

FIG 1. Brow lift. Intraoperative photographs show screws in the frontal bone used to secure sutures tunneled under the subcutaneous tissues toward the brow.
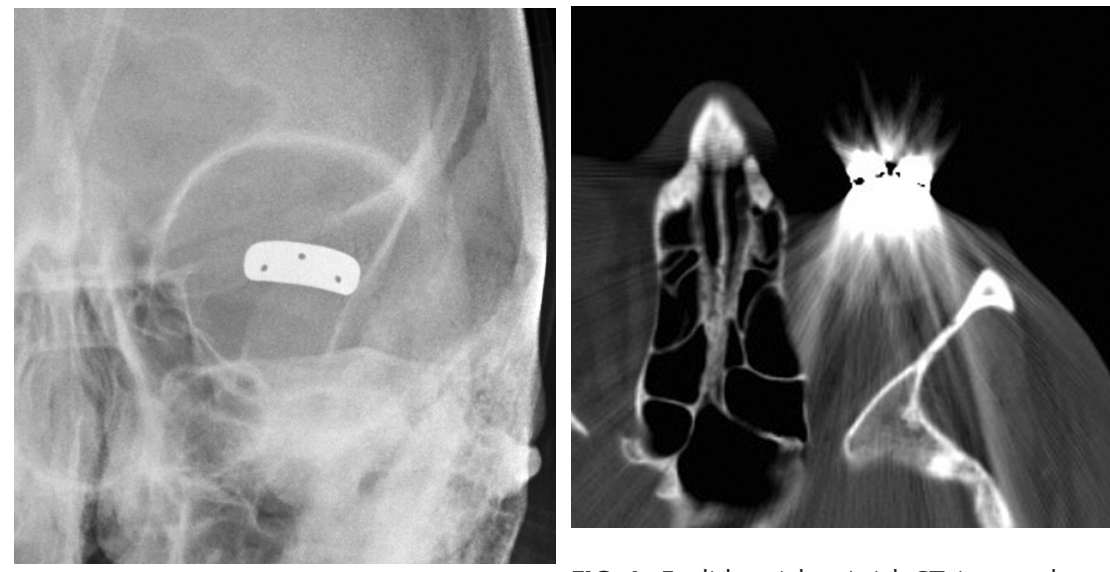

FIG 4. Eyelid weight. Axial CT image shows FIG 3. Eyelid weight. Frontal radiograph shows extensive streak artifacts related to the left a gold implant containing 3 drill holes at the eyelid weight, which obscures surrounding level of the left upper eyelid. structures.

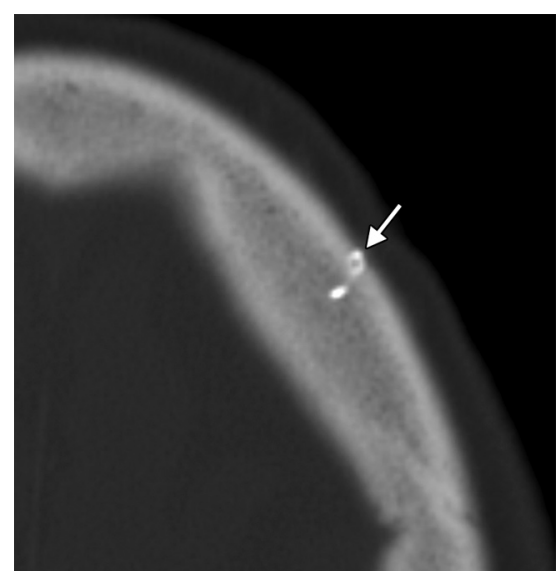

FIG 2. Brow lift. Axial CT image shows a metallic left frontal bone pin (arrow) used for suture fixation.



FIG 5. Eyelid weight. Axial post-contrast fatsuppressed T1-weighted image shows field inhomogeneity associated with the left eyelid weight (arrow).

ler sonography is an effective and noninvasive tool for evaluating arterial and venous flow through the pedicle of the buried free flap, whereby a sharp systolic upstroke should be evident in the artery and continuous flow should be observed in the vein (Fig 11). The examination can potentially avoid wound exploration to verify appropriate muscle perfusion and is typically performed on the first postoperative day. ${ }^{18}$ The arterial waveform of the graft should normally demonstrate a sharp systolic upstroke, while the vein may normally exhibit a continuous waveform and should be compressible, except at the site of the ring connector device. A good functional outcome correlates with normal muscle structure of the free flap depicted on MR imaging. ${ }^{19}$ Imaging may also be useful for measuring the graft thickness, ${ }^{20}$ which potentially relates to function.

\section{Fascia Lata Graft}

Autogenous fascia lata grafts can be used as the primary therapeutic option in static facial rebalancing or in conjunction with dynamic muscle reanimation. ${ }^{21}$ In particular, fascia lata slings can be used to improve oral competence and external nasal valve patency (Fig 12). The fascia lata graft is similarly inset into the subsuperficial musculoaponeurotic system plane and appears as a 

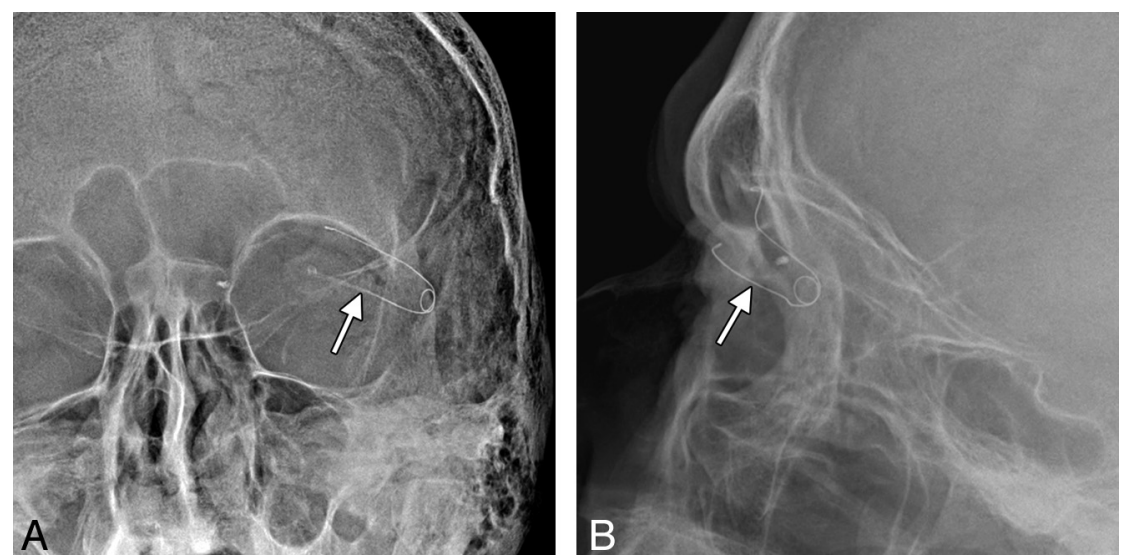

sion in facial paralysis. ${ }^{23,24}$ It is manufactured in thin 1- to 2-mm sheets, which can be cut into strips and implanted through small incisions. On CT, Gore-Tex slings appear as linear hyperattenuations (Fig 16). ${ }^{25}$ Although the use of Gore-Tex in facial reanimation eliminates donor site morbidity associated with the harvest of autologous grafts, the allograft is prone to complications, such as delayed wound infection. ${ }^{24}$

Disclosures: Mary E. Cunnane-UNRELATED: Other WorldCare Clinical, Comments: I was a radiologist for a clinical trial of a chemotherapy drug for head and neck cancer.

FIG 6. Eyelid spring. Frontal $(A)$ and lateral $(B)$ radiographs show that the inferior limb of the spring is positioned in the superior eyelid (arrows), while the superior limb is positioned along the orbital rim.
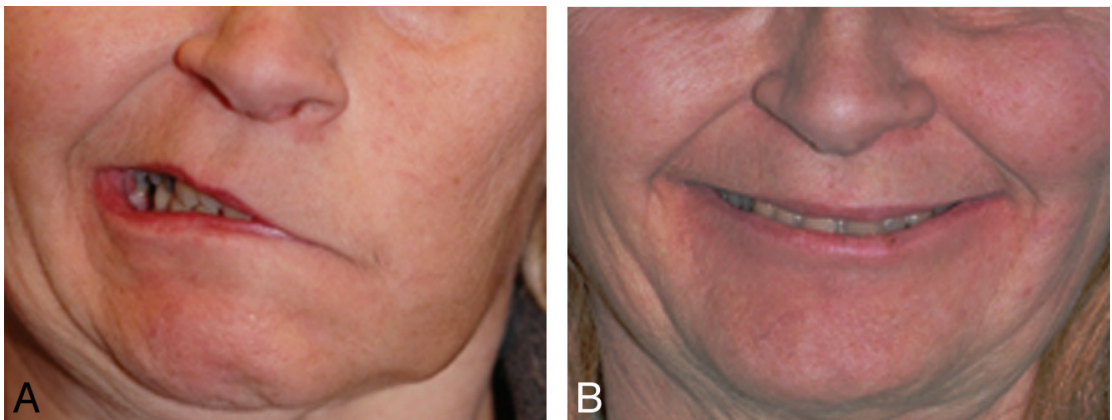

FIG 7. Gracilis free flap. Clinical photographs before $(A)$ and after $(B)$ gracilis free flap reanimation show marked restoration of the patient's smile.

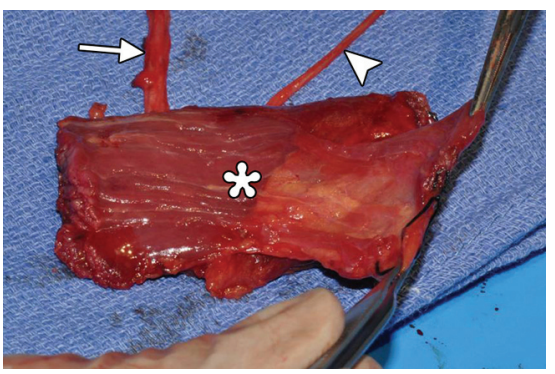

FIG 8. Gracilis free flap. Intraoperative photograph shows the harvested flap (asterisk) with an attached vascular pedicle (arrow) and nerve (arrowhead).

thin band of soft tissue that courses through the subcutaneous tissues of the face on cross-sectional imaging (Fig 13).

\section{Temporalis Flap}

The temporalis flap (temporalis muscle transposition) procedure is an effective option for reanimation of the smile. ${ }^{22}$ An approximately 1.5 -cm-wide strip of the midportion of the temporalis muscle is dissected off the calvaria and reflected in the subdermal plane from the zygomatic arch to the modiolus of the oral commissure (Fig 14). The course of the transposed temporalis muscle can be delineated on cross-sectional imaging as a thin band of soft tissue (Fig 15).

\section{Gore-Tex Sling Suspension}

Gore-Tex (expanded polytetrafluoroethylene) (W.L. Gore and Associates, Reisterstown, Maryland) can be used for static suspen-

\section{REFERENCES}

1. Foustanos A. Suture fixation technique for endoscopic brow lift. Semin Plast Surg 2008;22:43-49

2. Bladen JC, Norris JH, Malhotra R. Cosmetic comparison of gold weight and platinum chain insertion in primary upper eyelid loading for lagophthalmos. Ophthal Plast Reconstr Surg 2012;28: 171-75

3. Silver AL, Lindsay RW, Cheney ML, et al. Thin-profile platinum eyelid weighting: a superior option in the paralyzed eye. Plast Reconstr Surg 2009;123:1697-703

4. Schrom T, Thelen A, Asbach P, et al. Effect of 7.0 Tesla MRI on upper eyelid implants. Ophthal Plast Reconstr Surg 2006; 22:480-82

5. Marra S, Leonetti JP, Konior RJ, et al. Effect of magnetic resonance imaging on implantable eyelid weights. Ann Otol Rhinol Laryngol 1995; 104:448-52

6. Dinces EA, Mauriello JA Jr, Kwartler JA, et al. Complications of gold weight eyelid implants for treatment of fifth and seventh nerve paralysis. Laryngoscope 1997;107:1617-22

7. Fay A, Santiago YM. A modified Levine palpebral spring for the treatment of myogenic ptosis. Ophthal Plast Reconstr Surg 2012;28:372-75

8. Demirci H, Frueh BR. Palpebral spring in the management of lagophthalmos and exposure keratopathy secondary to facial nerve palsy. Ophthal Plast Reconstr Surg 2009;25:270-75

9. Levine RE, Shapiro JP. Reanimation of the paralyzed eyelid with the enhanced palpebral spring or the gold weight: modern replacements for tarsorrhaphy. Facial Plast Surg 2000;16:325-36

10. Gardner TA, Rak KM. Magnetic resonance imaging of eyelid springs and gold weights. Arch Ophthalmol 1991;109:1498

11. Chuang DC. Free tissue transfer for the treatment of facial paralysis. Facial Plast Surg 2008;24:194-203

12. Hadlock TA, Malo JS, Cheney ML, et al. Free gracilis transfer for smile in children: the Massachusetts Eye and Ear Infirmary Experience in excursion and quality-of-life changes. Arch Facial Plast Surg 2011;13:190-94

13. Boahene KD. Dynamic muscle transfer in facial reanimation. Facial Plast Surg 2008;24:204-10

14. Vakharia KT, Henstrom D, Plotkin SR, et al. Facial reanimation of patients with neurofibromatosis type 2. Neurosurgery 2012;70:237-43

15. Bianchi B, Copelli C, Ferrari S, et al. Facial animation with freemuscle transfer innervated by the masseter motor nerve in unilateral facial paralysis. J Oral Maxillofac Surg 2010;68:1524-29

16. Faria JC, Scopel GP, Busnardo FF, et al. Nerve sources for facial reanimation with muscle transplant in patients with unilateral fa- 

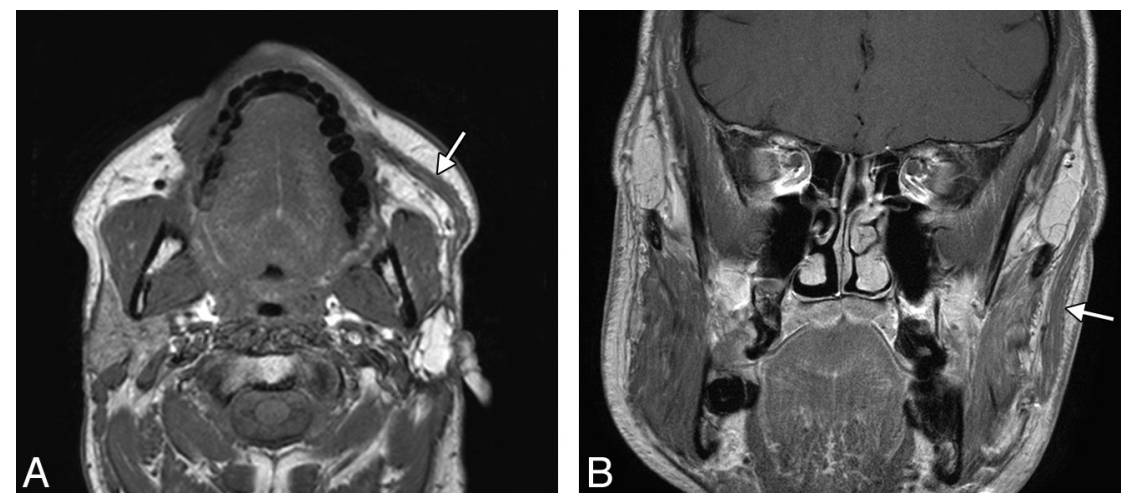

FIG 9. Gracilis free flap. Axial $(A)$ and coronal $(B)$ postcontrast T1-weighted MR images show a healthy gracilis flap (arrows), which extends from the zygomatic arch to the oral commissure following total left parotidectomy, with facial nerve sacrifice for resection of mucoepidermoid carcinoma.
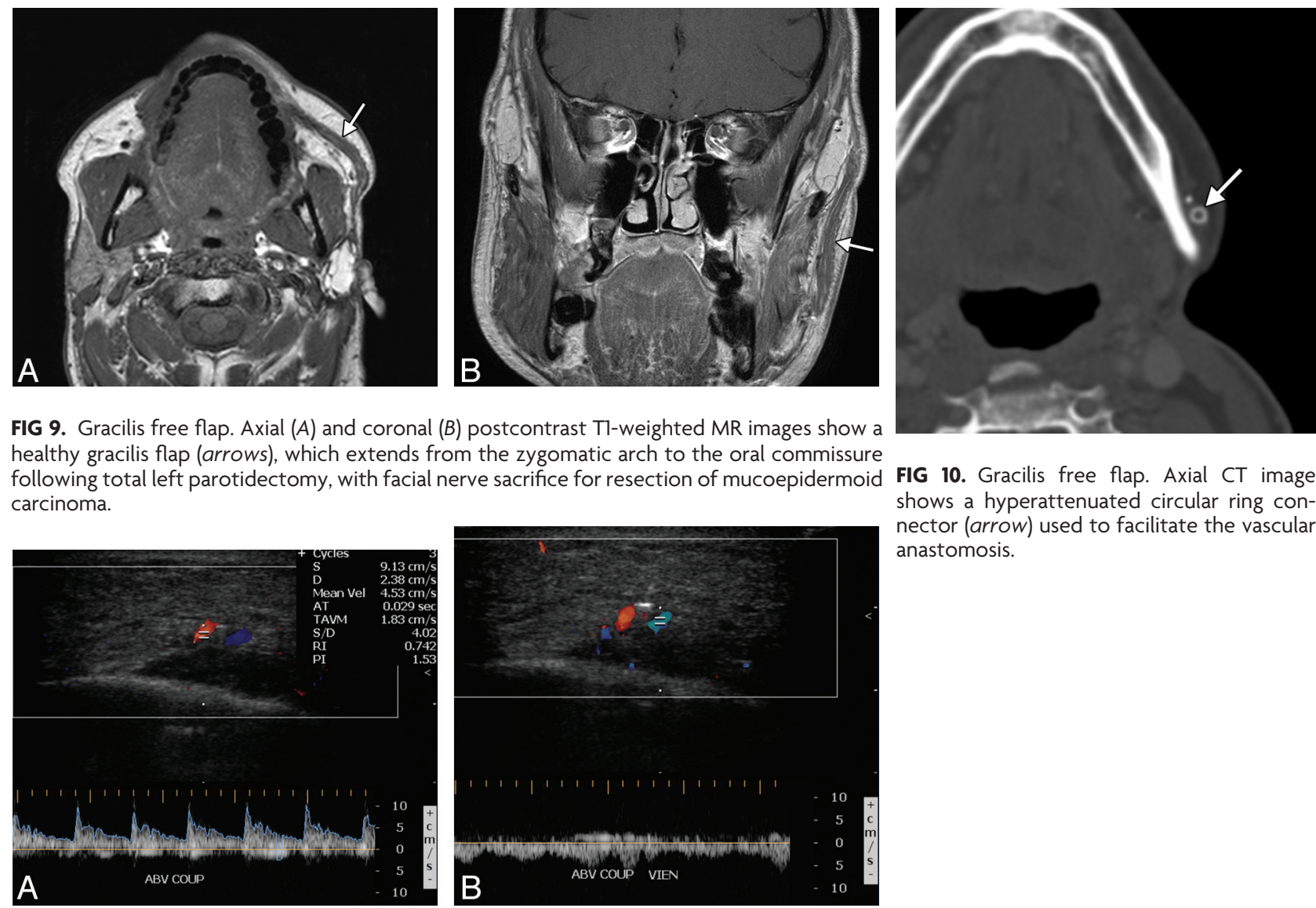

FIG 10. Gracilis free flap. Axial CT image shows a hyperattenuated circular ring connector (arrow) used to facilitate the vascular anastomosis

FIG 11. Gracilis free flap. Color Doppler sonographic images of the vascular pedicle show normal arterial $(A)$ and venous $(B)$ waveforms.

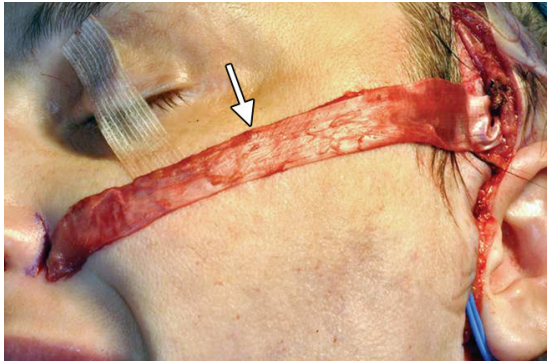

FIG 12. Fascia lata graft. Intraoperative photograph shows the prepared fascia lata graft (arrow) over its planned course toward the left nasal ala before implantation.

cial palsy: clinical analysis of 3 techniques. Ann Plast Surg 2007;59:87-91

17. Barker EV, Enepekides DJ. The utility of microvascular anastomotic devices in head and neck reconstruction. Curr Opin Otolaryngol Head Neck Surg 2008;16:331-34

18. Vakharia KT, Henstrom D, Lindsay R, et al. Color Doppler ultrasound: effective monitoring of the buried free flap in facial reanimation. Otolaryngol Head Neck Surg 2012;146:372-76

19. Ylä-Kotola TM, Kauhanen MS, Koskinen SK, et al. Magnetic resonance imaging of microneurovascular free muscle flaps in facial reanimation. Br J Plast Surg 2005;58:222-27

20. Salmi A, Ahovuo J, Tukiainen E, et al. Use of ultrasonography to evaluate muscle thickness and blood flow in free flaps. Microsurgery 1995; 16:601-05

21. Rose EH. Autogenous fascia lata grafts: clinical applications in reanimation of the totally or partially paralyzed face. Plast Reconstr Surg 2005;116:20-32, discussion 33-35

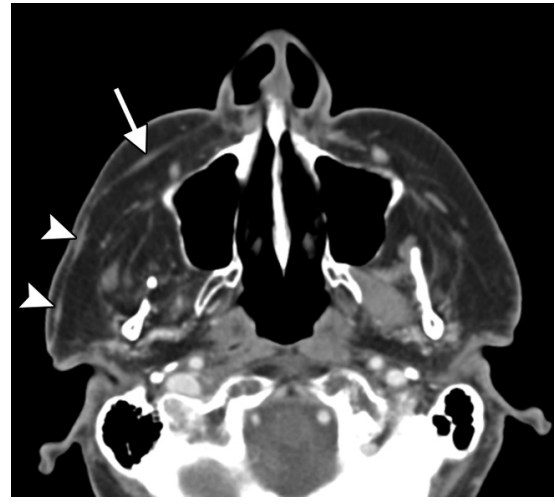

FIG 13. Fascia lata graft. The patient did not obtain optimal muscular function after the gracilis free flap procedure. Axial CT shows a tenuous right gracilis flap (arrowheads) and a linear band of soft tissue that extends from the gracilis flap to the right alar base, which corresponds to the fascia lata sling resuspension for external nasal valve correction (arrow).

22. White TP, Faulkner JA, Markley JM Jr, et al. Translocation of the temporalis muscle for treatment of facial paralysis. Muscle Nerve 1982;5:500-04

23. Liu YM, Sherris DA. Static procedures for the management of the midface and lower face. Facial Plast Surg 2008;24:211-15

24. Constantinides M, Galli SK, Miller PJ. Complications of static facial suspensions with expanded polytetrafluoroethylene (ePTFE). $\mathrm{La}$ ryngoscope 2001;111:2114-21

25. Schatz CJ, Ginat DT. Imaging of cosmetic facial implants and grafts. AJNR Am J Neuroradiol 2013;34:1674-81 

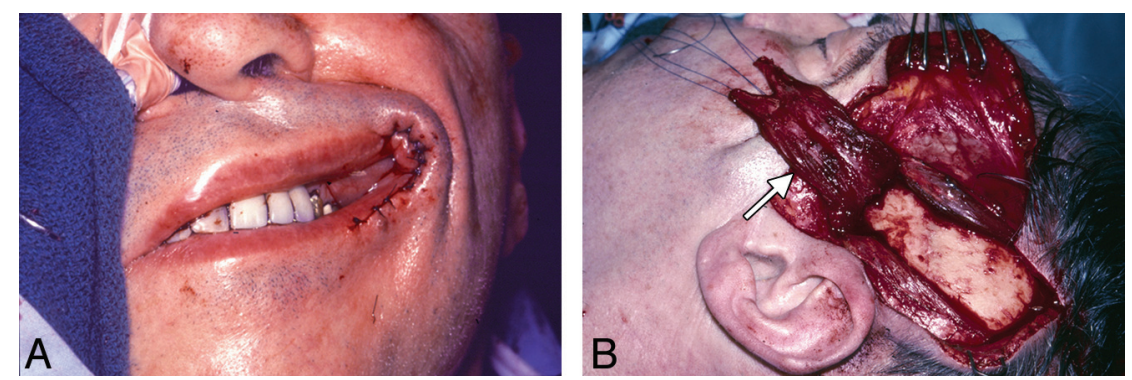

FIG 14. Temporalis flap. Intraoperative photographs show that the middle portion of the temporalis muscle (arrow) has been dissected free and transposed toward the oral commissure. The flap was subsequently tunneled beneath the subcutaneous tissues.


FIG 15. Temporalis flap. Axial T2 MR imaging $(A-C)$ and coronal T1 MR imaging $(D)$ show that the left temporalis muscle with the overlying fascia (arrows) is directed retrograde from the temporal fossa to the orbicularis oris.
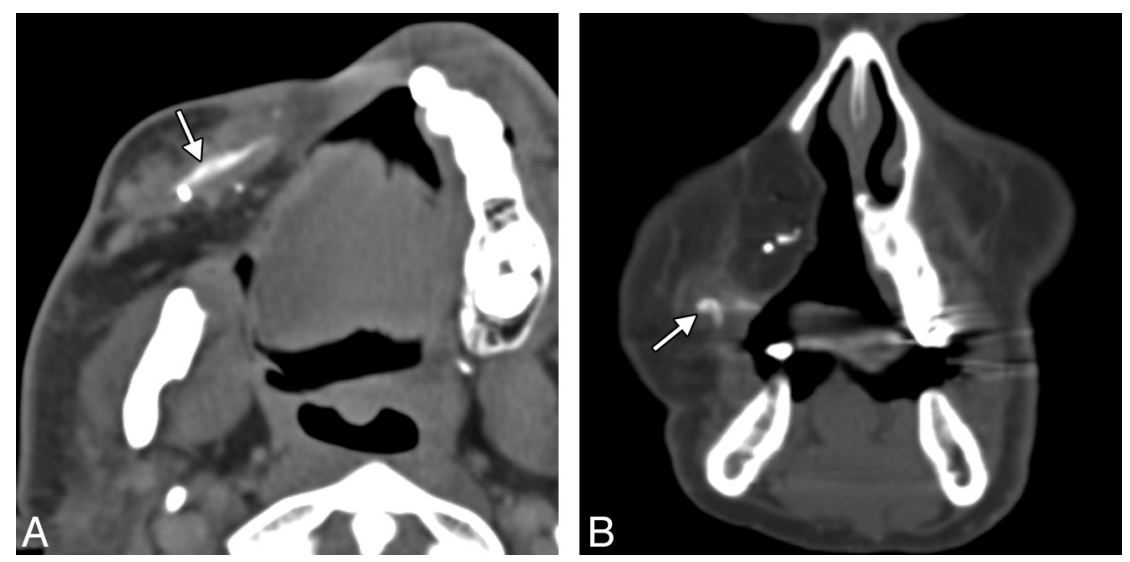

FIG 16. Gore-Tex sling. Axial $(A)$ and coronal $(B) C T$ images show the linear hyperattenuated strip of Gore-Tex that supports the right oral commissure (arrows). The patient is status post right complete maxillectomy with myocutaneous flap reconstruction. 